\title{
Increased Long-term Risk of Anal Fistula After Proctologic Surgery: A Case-Control Study
}

\author{
Julie Assaraf ${ }^{1}$, Elsa Lambrescak ${ }^{1}$, Jérémie H Lefèvre ${ }^{2,3}$, Vincent de Parades ${ }^{4}$, Josée Bourguignon ${ }^{1}$, \\ Isabelle Etienney ${ }^{1}$, Milad Taouk ${ }^{1}$, Patrick Atienza ${ }^{1}$, Jean-David Zeitoun ${ }^{1,5}$ \\ ${ }^{1}$ Proctologic Surgery, Groupe Hospitalier Diaconesses Croix Saint-Simon, Paris; ${ }^{2}$ General and Digestive Surgery, Saint-Antoine Hospital, \\ APHP, Paris; ${ }^{3}$ Department of Digestive Surgery, University Paris VI, Paris; ${ }^{4}$ Proctologic Surgery, Groupe Hospitalier Paris Saint-Joseph, Institut \\ Léopold Bellan, Paris; ${ }^{5}$ Gastroenterology and Nutrition, Saint-Antoine Hospital, APHP, Paris, France
}

Purpose: Anal fistula is a common condition in proctology, usually requiring surgical treatment. Few risk factors have been clearly identified based on solid evidence. Our research objective was to determine whether history of anal surgery was a risk factor for subsequent anal fistula.

Methods: We conducted a case-control study from January 1, 2012 through December 31, 2013 in our tertiary center, comprising 280 cases that underwent surgery for anal fistula and 123 control patients seeking a consultation for upper gastrointestinal symptoms. Patients with inflammatory bowel disease were excluded. For both cases and controls, the following variables were recorded: sex, any prior anal surgery, diabetes mellitus, infection with human immunodeficiency virus, and smoking status. For each variable, confidence interval and odds ratio (OR) were calculated.

Results: In univariate analysis, male sex $(73.2 \%$ vs. $31.7 \%, \mathrm{P}<0.0001)$, active smoking $(38.1 \%$ vs. $22 \%, \mathrm{P}=0.0015)$, and prior anal surgery $(16.0 \%$ vs. $4.1 \%, \mathrm{P}=0.0008)$ were associated with higher risk of anal fistula. In multivariate analysis, only male sex $(\mathrm{OR}, 5.5 ; 95 \%$ confidence interval $[\mathrm{CI}], 5.42$ to $9.10 ; \mathrm{P}<0.0001)$ and previous anal surgery $(\mathrm{OR}, 4.48 ; 95 \%$ $\mathrm{CI}, 1.79$ to $13.7 ; \mathrm{P}=0.0008)$ remained independently associated with anal fistula occurrence.

Conclusion: The epidemiology of anal fistula is poorly assessed despite the high frequency at which it is diagnosed. Our findings suggest that history of any kind of anal surgery is a risk factor for further onset of anal fistula. Surgeons and patients must be informed of this issue.

Keywords: Anal; Fistula; Surgery; Smoking; Epidemiology

\section{INTRODUCTION}

Anal fistula is one of the most common proctologic conditions. Its pathogenesis is poorly understood [1], and it has very few wellidentified risk factors, with the exception of Crohn disease, in which anal fistulas are not considered of cryptoglandular origin

Received: Mar 4, 2019 • Revised: Jun 14, 2019 - Accepted: Jun 18, 2019 Correspondence to: Julie Assaraf, M.D.

Proctologic Surgery, Groupe Hospitalier Diaconesses Croix Saint-Simon, 2bis place du général Leclerc, 94130 Nogent sur Marne, France

Tel: +33-661403996

E-mail: Julie.assaraf@gmail.com

ORCID: https://orcid.org/0000-0001-5679-9729

(C) 2021 The Korean Society of Coloproctology

This is an open-access article distributed under the terms of the Creative Commons Attribution NonCommercial License (https://creativecommons.org/licenses/by-nc/4.0) which permits unrestricted noncommercial use, distribution, and reproduction in any medium, provided the original work is properly cited.
[2]. Typically, the assumed causal mechanism is an obstruction of an anal crypt that leads to suppuration and aberrant tract constitution. The resulting fistula can then either remain chronic or evolve into a perianal abscess [3]. In all cases, treatment involves surgery, and several procedures often are needed, with extensive postoperative care and short- and long-term risk of fecal incontinence [4], even if emerging surgical techniques are less invasive [5, 6]. Only several rigorous reports are available regarding the risk factors for anal fistula [7]. Male sex is associated with a higher risk in some studies $[8,9]$. Smoking has been shown to increase the tendencies of anal fistulas and abscesses and is a risk factor for recurrence after surgery [10]. Our hypothesis was that prior history of anal surgery is a risk factor for subsequent anal fistula. This hypothesis, based on anecdotal observations of experienced practitioners, also relies on a possible link among loss of gland integrity, crypt disruption, and subsequent fistula formation. A recent case- 
control study [11] conducted in an Asian population has suggested this statistical association. In that report, prior anorectal surgery was an independent risk factor for anal fistula, as were environmental factors. However, the control population was a cohort referred to the department for anorectal complaints without fistula disease. These selection criteria could induce bias and underestimate history of anal surgery in the control group, especially if these patients seek medical advice for unsolved proctologic issues that could lead to further surgery. Our research objective was to further assess prior history of proctologic surgery as a risk factor for anal fistula through a case-control study.

\section{METHODS}

\section{Setting and population}

We performed a case-control study to compare the frequency of personal history of proctologic surgery in patients affected and not affected by anal fistula. All consecutive patients who underwent surgery for anal fistula of cryptoglandular origin between January 1, 2012 and December 31, 2013 in our tertiary center (Groupe Hospitalier Diaconesses Croix Saint-Simon, Paris) were included as cases in this retrospective work. According to French law, no classification by ethnic affiliation was made in this study. For patients who underwent several procedures, only the first was considered for this study. Cases with history of inflammatory bowel disease (IBD), either Crohn disease or ulcerative colitis, were excluded from this study. Other causes of anal fistula such as actinomycosis, tuberculosis, and lymphogranuloma venereum of rectal foreign bodies were recorded. Patients with anovaginal fistula were not included in this study.

For every case, we reported the type of previous surgery. The control cohort was constructed through inclusion of all consecutive patients seeking medical advice from one of the authors for any kind of upper gastrointestinal symptom over the same period. Namely, epigastric pain, gastroesophageal reflux symptoms, or any type of dyspepsia according to the Rome III criteria were considered eligible for inclusion in the control group, except if an IBD was recorded.

The following variables were recorded both for cases and controls: any prior anal surgery (and for which condition), diabetes mellitus, human immunodeficiency virus (HIV) infection (cases were tested routinely, and HIV status was retrospectively recorded for controls), smoking status, and any condition associated with an immunocompromised status. The latter data were collected since they are frequently cited as risk factors for anal fistula. For the cases, personal history of surgery for anal fistula could either mean that the current episode was a recurrence or a new fistula. Since choice between the two hypotheses was tricky, we decided that any previous operation for anal fistula dating back more than five years would be unlikely to be a recurrence and would therefore be considered as history of proctologic surgery. Data were collected through manual review of medical records for both cases and controls by the first author of the paper. Previous history of anal surgery was systematically assessed by direct questioning in both cohorts.

The work has been reported in line with the STROCCS (Strengthening the Reporting of Cohort Studies in Surgery) guideline.

\section{Ethics}

Our study used unidentified patient data that did not require approval from an ethics committee according to French law. However, use of this database for public health research was submitted to and accepted by the French National Commission for Data Protection (Commission Nationale de l'Informatique et des Libertés, registration: 1988935v0). According to the World Medical Association's Declaration of Helsinki 2013, this study was registered in the Research Registry (UIN 4859).

\section{Statistical analysis}

Quantitative variables were presented as median (interquartile range) and compared with Student t-test. Qualitative variables were presented as count (\%) and compared by Fisher exact test. Any variable achieving $\mathrm{P}<0.2$ in univariate analysis was included in the multivariate analysis. All tests were two sided with a significance level set at 5\%. All analyses were performed using SAS ver. 9.4 (SAS Institute, Cary, NC, USA).

\section{RESULTS}

There were 280 cases and 123 controls in the study (Table 1). In the case group, 205 patients (73.2\%) were male with a median age of $45.1 \pm 13.6$ years. Forty-five patients $(16.0 \%)$ were recorded as having history of proctologic surgery. Previous anal surgeries reported among cases were hemorrhoids (51.1\%), anal fissure $(31.1 \%)$, previous anal fistula dating back more than 5 years

Table 1. Patient characteristics

\begin{tabular}{lcc}
\hline Characteristic & Cases $(\mathrm{n}=280)$ & Controls $(\mathrm{n}=123)$ \\
\hline Male sex & $205(73.2)$ & $39(31.7)$ \\
Age (yr) & $45.1 \pm 13.6$ & $42.2 \pm 14.7$ \\
Prior anal surgery & $45(16.01)$ & $5(4.1)$ \\
HIV infection & $17(6.1)$ & $3(2.4)$ \\
Active smoking & $107(38.1)$ & $27(22.0)$ \\
Diabetes mellitus & $12(4.3)$ & $3(2.4)$ \\
Fistula classification & & $\mathrm{NA}$ \\
$\quad$ High intersphincteric fistula & $45(16.0)$ & \\
Transsphincteric & $195(69.6)$ & \\
Intersphincteric & $12(4.3)$ & \\
Subcutaneous & $49(17.5)$ & \\
\hline
\end{tabular}

Values are presented as number (\%) or mean \pm standard deviation. HIV, human immunodeficiency virus; NA, non applicable. 


\section{$\begin{array}{rrr}\text { Annals of } & \text { Increased Long-ter } \\ \text { Coloproctology } & \text { Julie Assaraf, et al. }\end{array}$}

Table 2. Uni- and multivariate analyses of factors associated with anal fistula

\begin{tabular}{|c|c|c|c|c|c|c|}
\hline \multirow{2}{*}{ Variable } & \multicolumn{3}{|c|}{ Univariate analysis } & \multicolumn{3}{|c|}{ Multivariate analysis } \\
\hline & Case & Control & P-value & $\mathrm{OR}$ & $95 \% \mathrm{Cl}$ & P-value \\
\hline Male sex & $73.2 \%$ & $31.7 \%$ & $<0.0001$ & 5.50 & $3.42-9.10$ & $<0.0001$ \\
\hline Age (yr) & $45.1 \pm 13.6$ & $42.2 \pm 14.7$ & 0.0520 & NA & NA & 0.0637 \\
\hline Prior anal surgery & $16.0 \%$ & $4.1 \%$ & 0.0008 & 4.48 & $1.79-13.7$ & 0.0008 \\
\hline HIV & $6.1 \%$ & $2.4 \%$ & 0.1221 & 1.42 & $0.42-6.63$ & 0.5930 \\
\hline Smoking & $38.1 \%$ & $22.0 \%$ & 0.0015 & 1.64 & $0.96-2.86$ & 0.0725 \\
\hline Diabetes mellitus & $4.3 \%$ & $2.4 \%$ & 0.3703 & NA & NA & $\mathrm{NI}$ \\
\hline
\end{tabular}

OR, odds ratio; $\mathrm{Cl}$, confidence interval; NA, not applicable; HIV, human immunodeficiency virus; $\mathrm{NI}$, not included.

(11.1\%), and condyloma (6.7\%).

There was no patient with documented or suspected lymphogranuloma venereum, rectal foreign bodies, or tuberculosis. Only 1 patient had actinomycosis-related fistula with no previous anal surgery.

HIV infection, active smoking, and diabetes mellitus were listed in 17 patients (6.1\%), 107 patients (38.1\%), and 12 patients (4.3\%), respectively. Most fistulas were of transsphincteric location (69.9\%), while high intersphincteric fistula (16\%), subcutaneous (17.5\%), and intersphincteric (4.3\%) tracts were less common. The average age of the controls was $42.2 \pm 14.7$ years old, 39 $(31.7 \%)$ were male, and 5 (4.1\%) had history of anal surgery. HIV infection, active smoking, and diabetes mellitus were detected in 3 (2.4\%), 27 (22\%), and $3(2.4 \%)$ of the control patients, respectively.

In univariate analysis, male sex $(73.2 \%$ vs. $31.7 \%, \mathrm{P}<0.0001)$, active smoking ( $38.1 \%$ vs. $22 \%, \mathrm{P}=0.0015)$, and prior anal surgery $(16.01 \%$ vs. $4.1 \%, \mathrm{P}=0.0008)$ were statistically more frequent in patients with anal fistula compared to those from the control group (Table 2). After multivariate analysis, male sex (odds ratio [OR], 5.5; 95\% confidence interval [CI], 5.42 to 9.10; $\mathrm{P}<0.0001$ ) and previous history of anal surgery (OR, $4.48 ; 95 \% \mathrm{CI}, 1.79$ to 13.7; $\mathrm{P}=0.0008)$ remained significantly associated with anal fistula (Table 2).

\section{DISCUSSION}

In this case-control study involving patients with and without anal fistula, we found that personal history of anal surgery was statistically more frequent in patients with anal fistula compared to those with no such condition (OR, 4.48).

Our study has several strengths. First, our study sample was quite large for both the anal fistula cases and control patients. Second, recruitment of cases was performed by experts in surgical proctology in our tertiary center, thereby providing high accuracy regarding diagnosis. Controls were enrolled over the same time period. In addition, the control patients were carefully chosen to reduce the risk of bias. The control patients had no anorectal issue, and patients with any type of IBD were excluded from the study. Third, the data were of good quality due to a rigorous collection process and a manual review performed by the first author. Last, other clinical data such as HIV status, diabetes mellitus, or active smoking were collected for inclusion in multivariate analysis, reducing the risk of unmeasured confounding factors.

Our findings raise several issues regarding long-term complications of any type of proctologic surgery. Very few findings about the epidemiology of anal fistula could be found in the literature, though our results are in line with a recent report from a Chinese population [11]. We believe that these limited data support the hypothesis of increased long-term risk of anal fistula after anal surgery. This study aimed to identify risk factors for anal fistula among a large range of issues including lifestyle factors and certain medical conditions. They found that previous anal surgery was a risk factor for anal fistula, with OR $(2,054)$. Even after multivariate adjustment, we found an almost five-fold increased risk of anal fistula in patients with history of surgery for a proctologic condition. Therefore, patients should be informed about such a risk before any anal surgery.

Previous reasons for anal surgery reported among cases were hemorrhoids (51.1\%), anal fissure (31.1\%), previous anal fistula dating back more than 5 years (11.1\%), and condyloma (6.7\%). These rates correspond to those observed in our clinical practice. This finding suggests that no type of anal surgery is more likely to produce further anal fistula.

However, another body of literature has studied risk factors for anal fistulas in IBD. Sahnan et al. $[12,13]$ have shown that independent predictors of fistula formation after anorectal abscess include Crohn disease (hazard ratio [HR], 3.51), ulcerative colitis (HR, 1.82), female sex (HR, 1.18), age between 41 and 60 years (HR, 1.85), and location of fistula (intersphincteric or ischiorectal). In another study, patients with Crohn disease were more than twice as likely to develop a fistula than patients without Crohn disease (32.6\% vs. $14.9 \%$; OR, 2.5; 95\% CI, 1.7 to 3.7; $\mathrm{P}<0.001$ ).

Our research has limitations precluding definitive conclusions. It is a case-control study, and the retrospective data collection generates risk of errors. In addition, anal fistula among subjects with history of anal surgery for fistula treatment can either be recurrence or a new episode. To minimize this potential bias, we 
excluded patients who underwent surgery for anal fistula less than 5 years before inclusion considering that recurrence generally occurs within 5 years after initial surgery. Also, a prospective study that assessed the long-term recurrence rate after anal surgery found that all fistulas occurred before 24 months [14]. In our study, smoking was not associated with greater risk of anal fistula, in contrast with published epidemiological data $[10,11,15]$. We cannot exclude a lack of statistical power since univariate analysis showed a significant association but multivariate analysis did not. Moreover, since we wanted to study whether male sex was a risk factor for anal fistula, we did not match cases and controls by sex, which could have induced bias.

Our study cannot establish any causal relation between previous anal surgery and anal fistula occurrence. Furthermore, this study is quite limited in determining if a type of proctologic surgery is more likely to increase risk of further anal fistula compared to others. We chose not to perform subgroup analysis so as to avoid multiple testing, in particular since there was a small number of patients in each subgroup.

A final point concerns the pattern of fistulas reported in this study. We found $69.9 \%$ of the fistulas in this study to be transsphincteric, which is a higher incidence than usually reported. The high rate in this study most likely resulted from the tertiary center location and variable patient epidemiology in our department.

In conclusion, our findings suggest that anal surgery is associated with increased long-term risk of anal fistula. Even though this requires confirmation, ideally in a prospective manner, patients and physicians should be aware of this long-term risk.

\section{CONFLICT OF INTEREST}

No potential conflict of interest relevant to this article was reported.

\section{REFERENCES}

1. Sugrue J, Nordenstam J, Abcarian H, Bartholomew A, Schwartz JL, Mellgren A, et al. Pathogenesis and persistence of cryptoglandular anal fistula: a systematic review. Tech Coloproctol 2017;21:
425-32.

2. Scharl M, Rogler G. Pathophysiology of fistula formation in Crohn's disease. World J Gastrointest Pathophysiol 2014;5:205-12.

3. Hamadani A, Haigh PI, Liu IL, Abbas MA. Who is at risk for developing chronic anal fistula or recurrent anal sepsis after initial perianal abscess? Dis Colon Rectum 2009;52:217-21.

4. Bokhari S, Lindsey I. Incontinence following sphincter division for treatment of anal fistula. Colorectal Dis 2010;12:e135-9.

5. Limura E, Giordano P. Modern management of anal fistula. World J Gastroenterol 2015;21:12-20.

6. Sirikurnpiboon S, Awapittaya B, Jivapaisarnpong P. Ligation of intersphincteric fistula tract and its modification: results from treatment of complex fistula. World J Gastrointest Surg 2013;5: 123-8.

7. Sainio P. Fistula-in-ano in a defined population: incidence and epidemiological aspects. Ann Chir Gynaecol 1984;73:219-24.

8. Ramanujam PS, Prasad ML, Abcarian H, Tan AB. Perianal abscesses and fistulas: a study of 1023 patients. Dis Colon Rectum 1984;27:593-7.

9. Read DR, Abcarian H. A prospective survey of 474 patients with anorectal abscess. Dis Colon Rectum 1979;22:566-8.

10. Devaraj B, Khabassi S, Cosman BC. Recent smoking is a risk factor for anal abscess and fistula. Dis Colon Rectum 2011;54:681-5.

11. Wang D, Yang G, Qiu J, Song Y, Wang L, Gao J, et al. Risk factors for anal fistula: a case-control study. Tech Coloproctol 2014;18: 635-9.

12. Sahnan K, Askari A, Adegbola SO, Tozer PJ, Phillips RK, Hart A, et al. Natural history of anorectal sepsis. Br J Surg 2017;104:185765.

13. Sahnan K, Askari A, Adegbola SO, Warusavitarne J, Lung PFC, Hart A, et al. Persistent fistula after anorectal abscess drainage: local experience of 11 years. Dis Colon Rectum 2019;62:327-32.

14. Zimmerman DD, Mitalas LE, Schouten WR. Long-term functional outcome and risk factors for recurrence after surgical treatment for low and high perianal fistulas of cryptoglandular origin. Dis Colon Rectum 2009;52:1196-7.

15. Zheng LH, Zhang AZ, Shi YY, Li X, Jia LS, Zhi CC, et al. Impact of smoking on anal abscess and anal fistula diseases. Chin Med J (Engl) 2018;131:1034-7. 